\title{
A Research on the Problem of Pupil Teacher (B.Ed.) In Acquiring the Skill of Introducing a Lesson during Micro Teaching
}

\author{
Mr. Jubraj Khamari ${ }^{1}$, Dr. P. Hanspal ${ }^{2}$, Dr. S.N. Mahapatra ${ }^{3}$, Dr. N. Guru ${ }^{4}$, \\ Dr. U. P. Khadenga ${ }^{5}$ \\ ${ }^{I}$ Deptt. Of School Of Education, MATS University, Gullu, Arang, Raipur, (C.G) - INDIA, \\ ${ }^{2}$ Deptt. Of School Of Education, MATS University, Gullu, Arang, Raipur, (C.G) - INDIA, \\ ${ }^{3}$ Deptt. Of DPIASE, Beherampur University, Bhanja Bihar, Beherampur, Odisha-INDIA, \\ ${ }^{4}$ Deptt. Of Dr. RNIASE Cuttack, Uttkal University, Vani Bihar, Cuttack, Odisha - INDIA, \\ ${ }^{5}$ Deptt. Of Dr. PMIASE, Sambalpur University, Jyoti Bihar, Sambalpur, Odisha-INDIA,
}

\begin{abstract}
The new innovation like team teaching, simulated teaching, program learning and interaction analysis, 'Micro Teaching' is a very important mean for(pupil-teacher) pre-service as well as in-service teacher to develop and improve their pedagogical skills with a small group of pupil within a very short time with very short content material. So far as the core-teaching skill is concerned, the pupil teacher (B.Ed. students) faced so many problems during micro teaching while acquiring the each and every skill. Hence researchers did study such a research on this problem with special reference to the Skill of Introducing a Lesson to find out the problems so as to give the remedial measures with analysis and interpretation of collected data with Simple Percentage Method through Questionnaire from selected sample with Purposive Sampling procedure out of total population of all the B.Ed. colleges delaminating to Raipur district only of Chhattisgarh state to complete the research work smoothly, successfully and innovatively to achieve the stated objectives correlating the aspect hypothesis so far as the Normative Survey Method of methodology of educational research is concerned. Keywords : Core-teaching Skill, Logic behind Introduction, Micro Teaching, Pedagogical Skill, Pupil Teacher.
\end{abstract}

Submitted Date 17 June 2013

Accepted Date: 22 June 2013

\section{Introduction}

The new innovation like team teaching, simulated teaching, program learning and interaction analysis, "Micro Teaching" is a very important mean for pre-service as well as in-service teacher to develop and improve their pedagogical skills with a small group of pupil within a very short time with very short content material. So far as the core-teaching skill is concerned the Australian Advisory Committee on Research and Development in Education have analyzed 140 skills, Allen and Ryan(1969) of the Standford University(USA) have suggested 14 skills where as Baroda General Teaching Competence scale was evolved with emphasis on 21 skills. But Dr. B.K. Passi has prescribed 13 skills which were developed on the bases of researches of Passi(1976) then E.C. Singh(1976-79), Janjira(1978) and Department of Teacher Education, the NCERT. The model was developed by Dr. Passi, Shah and Others at the center of Advance Study in Education Baroda. The pupil teachers (inservice and pre-service teachers) of B.Ed. class have been acquiring all these pedagogical skills in general and the 13 skills developed by Dr. Passi in particular and 7 skills as prescribed by B.Ed. syllabus in special in Micro Teaching.

In Micro teaching, first the pupil teacher receives a live of taped demonstration of teaching skill. Then he teaches a micro lesson for 5-10(small group) pupils taking a single concept. This Micro lesson is videotaped. Soon after the lesson, the pupil teacher views the lesson on the video tape. He also receives feedback from his supervisor and peers. Then the pupil teacher re-plans the lessons on the basis of the feedback received from the supervisor and peers and re-teaches the same content to a different group of pupil. After teaching, this lesson is again reviewed and feedback is given to the pupil teacher by the supervisor and peers. The cycle of microteaching (teach, critique, re-teach, re-critique) continues till the pupil teacher attains mastery over the particular skill. During this process pupil teacher faced a lot of problems while conducting a micro lesson. Hence in this research study researchers conducted a research on a particular skill i.e. the Skill of Introducing a Lesson to find out the problems and suggest the remedial measures. 


\subsection{Core Teaching Skills}

\section{Operational Term}

Observation of class room, various research studies and different theories of learning specify a group of teaching acts or behaviors intend to facilitate pupils learning directly or indirectly which are basic to teaching i.e. a group of teaching skill is termed as Core Teaching Skills.

\subsection{Logic Behind Introduction}

Before presentation introduction is too much importance as a reason introduction is just like the 'Mukhasala' of a temple, 'Preface' of a book, well begun half down and like preamble of Indian Constitution what we say logic behind introduction before presentation of a topic so far as micro teaching is concerned.

\subsection{Micro Teaching}

Micro Teaching is a scale down teaching encounter, scale down in term of class size (5-10 pupils), lesson length (5-10 minutes) and teaching complexity to provide pupil teachers for immediate diagnostic evaluation of teacher performance developing and acquiring pedagogical skill.

\subsection{Pedagogical Skill}

Pedagogical skill means all those skill which are meant to be develop teaching performance of the pupil teacher, by the pupil teacher and for the pupil teacher within himself for his better performance those are identified as like Australian Advisory Committee On Research \& Development in Education 140, Allen \& Rayan (1969) of Stand Ford University (USA) 14, Baroda General Teaching Competancy Scale 21 and Dr. B.K. Passi(1976) and associate has prescribed 13skill. Those are:-
1) Skill of writing instructional objectives
2) Skill of introducing a lesson
3) Skill of fluency in questioning
4) Skill of proving question
5) Skill of explaining
6) Skill of illustration with example
7) Skill of stimulus variation
8) Skill of silence and non-verbal cues
9) Skill of using blackboard
10) Skill of achieving closer
11) Skill of recognizing attending behavior
12) Skill of increasing pupils participation
13) Skill of reinforcement

\subsection{Pupil Teacher}

In this research study the researcher termed as pupil teacher to all the B.Ed. Students of teacher training institution selected as sample and constituted the population of the research work.

\section{$3.1 \quad$ Objectives}

\section{Objectives \& Hypotheses}

1. To find out the problems in acquiring Skill of Introducing a Lesson during micro teaching.

2. To find out the reasons behind this problem while acquiring Skill of Introducing a Lesson during micro teaching.

3. To suggest remedial measures to reduce and remove all that problems to develop the pedagogical skill.

\subsection{Assumptions}

1. Pupil teachers have the problems of using accurate techniques of introducing a lesson.

2. Pupil teachers cannot use each and every techniques of the introducing a lesson successfully.

3. Pupil teachers do not have the knowledge on the logics \& various techniques of introducing a lesson.

\subsection{Hypotheses}

1. If the pupil teachers get sufficient content knowledge on the logics and techniques behind introduction, then they can acquire the skill of the introducing a lesson skillfully.

2. If the pupil teachers get sufficient content knowledge about different techniques of introduction then they can acquire the skill of introducing a lesson skillfully. 
3. If the pupil teachers get sufficient knowledge on techniques of using different techniques of introduction then they can acquire the skill of introducing a lesson skillfully.

\subsection{Method:-}

\section{Methodology}

Researchers selected and used Normative Survey Research method for this study.

\subsection{Population:-}

Researchers have selected all the pupil teachers of all the B.Ed. colleges in Raipur District of Chhattisgarh state to constitute as the population of this research study.

\subsection{Sample:-}

Researchers have selected one college by Purposive Sampling Method out of total population.

\subsection{Tool:-}

Researchers have used Questionnaire to collect data from the sample as relevance tool in the study.

\subsection{Statistical Technique:-}

Researchers used the Simple Percentage method for analyze \& interpretation of the collected data.

\subsection{Findings :}

\section{Findings \& Suggestions}

5.1.1 Most of the pupil teachers have the knowledge about meaning of micro teaching, skill of introducing a lesson and only one technique (question-answer technique based on previous knowledge).

5.1.2 Most of the pupil teachers have the knowledge about the objectives of skill of introducing a lesson and reasons behind introduction.

5.1.3 Most of the pupil teachers faced problems due to lack of sufficient content knowledge about logics \& techniques behind introduction, different type of techniques of introducing a lesson and techniques of using different types of techniques of introducing a lesson.

\subsubsection{Suggestions}

5.2.1 Teacher educator should educate the pupil teacher with sufficient content knowledge about micro- teaching, pedagogical skill, skill of introduction and a list of different techniques of introductions.

5.2.2 Teacher educator should educate the pupil teacher with deep knowledge of techniques of using different types of techniques of introducing a lesson like questioning, story -telling, role playing, dramatization, audio visual aids, experimentation, demonstration etc.

5.2.3 Teacher educator should prepare ideal lesson with suitable example to educate and motivate the pupil teachers to develop the skill of introducing a lesson with using each and every types of techniques of skill of introducing a lesson.

\section{References}

[1] Sahoo, C., (2000). Educational Technology. Sambalpur : Menaka Prakashan.

[2] Walia, J.S., (2000). Educational Technology. Punjab: Paul Publisher Jalandhar city.

[3] Bloom, B. S., etal. (1956). Taxonomy of Educational Objectives : Cognitive Domai. New York : David Mc Kay Co. Inc.

[4] Agrawal, J.C., (2009). Educational Technology and Management. Agra: Agrawal Publication.

[5] Bhattacharya, S.K., (2006). Educational technology. New Delhi: Abhishek Publication.

[6] Sharma, R. A., (1993). Advanced Educational Technology. Meerut : Eagle Book International.

[7] Passi, B.K., (1976). Becoming Better Teacher : Micro teaching Approach. Ahmedabad: Sahi Muranalaya.

[8] Best, John \& Prentice, W.,( 1978).Research in Education, New Delhi: Hall of India

[9] Allen, Dwight and Ryan, K. (1969). MicroTeaching. London : Addison Wesley Publishing Company.

[10] Sharma, A.R., (1989). Educational Technology. Agra : Binod Pustak Mandir.

[11] Buch, M.B., (1983). Fourth Survey of Educational Research, New Delhi. N.C.E.R.T.

[12] Sankhala, D.P., (2007). Educational Technology. New Delhi : Adhyayan Publishers \& Distributors.

[13] Buch, M.B., (1987). Third Survey of Educational Research, New Delhi N.C.E.R.T

[14] Sampath, K.etal., (1990). Introduction To Educational Technology. New Delhi : Sterling Publishers. 